\title{
Clarification of Factor Five with the help of the AB5C Model
}

\author{
JOHN A. JOHNSON* \\ Pennsylvania State University, DuBois Campus, U. S. A.
}

\begin{abstract}
The Abridged Big Five-Dimensional Circumplex (AB5C) Model of Hofstee, De Raad and Goldberg (1992) represents trait terms as blends of factors. Analyses suggest that different scales for measuring Factor $V$ (Mentality) may reflect blends of this factor with either Factor III (Constraint) or Factor I (Extraversion/Surgency). Measures saturated primarily by Factor $V$ alone $(V+V+$ in the AB5C terms of Hofstee et al.) represent Creative Mentality. Measures that blend Factor $V$ with the positive pole of Factor III represent Constrained Mentality $(V+I I I+)$, with the negative pole, Unconstrained Mentality $(V+I I I-)$. Measures that blend Factors $V$ and I represent Surgent Mentality $(V+I+)$. While all of these variants are perfectly valid forms of Factor $V$, Creative Mentality seems to be the central core of Factor $V$ and is represented by the Openness to Ideas and Openness to Aesthetics Scales of Costa and McCrae (1992) and by the Generates Ideas and Culture Scales of Hogan and Hogan (1992).
\end{abstract}

\section{INTRODUCTION}

This article addresses the following two questions: (i) How can we account for differences of opinion about Factor V of the 'Big Five' or Five-Factor Model of personality (FFM; Digman, 1990)? and (ii) What is the 'best' (most valid, useful, satisfactory) conception of Factor V? In response to the first question, I suggest that Factor $\mathrm{V}$ represents a broad psychological domain, of which different subdomains have been emphasized by different researchers. I answer the second question by arguing that the best conception of Factor $V$ can be found in a point on which these researchers actually agree: the core of Factor $\mathrm{V}$ is creativity.

I support these arguments by presenting new empirical findings and by linking these findings to earlier research (Kolb, 1976; Royce, 1964; Welsh, 1975) whose relevance to Factor $\mathrm{V}$ has remained largely unrecognized. Finally, this article describes how viewing Factor $\mathrm{V}$ within the context of human evolution generates some new, testable hypotheses about the fifth factor.

\footnotetext{
*All correspondence concerning this article should be addressed to John A. Johnson, Department of Psychology, Pennsylvania State University, DuBois Campus, DuBois, PA 15801, U.S.A. Internet j5j@psuvm.psu.edu.
} 
This article builds upon previous research with the Abridged Big Five-Dimensional Circumplex (AB5C; Hofstee, De Raad and Goldberg, 1992; Johnson, 1992; Johnson and Ostendorf, 1993) to clarify points of agreement and disagreement across ratingscale measures of the Big Five. Johnson and Ostendorf (1993) suggested that creativity is the common theme tapped by different adjectival measures of Factor V. We also suggested that some of these measures assess a blend of Factor $\mathrm{V}$ and Factor I, whereas others assess a blend of Factors $V$ and III. We proposed that blends of Factors V and I represent what others have called openness to experience (McCrae and Costa, 1985) or expressive intellect (Peabody and Goldberg, 1989). On the other hand, blends of Factors V and III represent what Peabody and Goldberg (1989) called controlled intellect.

\section{The aim of the present study}

This article extends these AB5C analyses in two ways. Firstly, it extends the AB5C analysis from simple rating scales to two more complex personality questionnaires constructed explicitly around the FFM: the revised NEO Personality Inventory (NEO-PI-R; Costa and McCrae, 1992b), and the revised Hogan Personality Inventory (HPI; Hogan and Hogan, 1992). Secondly, the article examines more closely how the source of impulsivity in the unconstrained variants of Factor V (Openness or Expressive Intellect) can derive either from the positive pole of Factor I (Extraversion/ Surgency) or the negative pole of Factor III (Constraint).

\section{The Abridged Big Five-Dimensional Circumplex (AB5C)}

Hofstee et al. (1992) observed that individual trait words only rarely reflect just one of the Big Five factors. In fact, a complete depiction of a trait in terms of the FFM would include its loading on all five factors. Empirically, however, very few (3 per cent of a comprehensive list of 540) traits show appreciable $(0.20$ or greater) loadings on three factors, and none on four or five factors. The AB5C therefore 'abridges' a full five-dimensional model to a two-dimensional model. In $\mathrm{AB} 5 \mathrm{C}$ terms, a trait is depicted by the two factors, a primary and a secondary, that best describe it.

Hofstee et al. (1992) note that different collections of trait terms designed to assess the same factor could conceivably measure very different constructs if the secondary aspects of the traits differ. For example, if one used ratings of alert, ambitious, firm, and purposeful (all III $+\mathrm{I}+$ ) to measure conscientiousness (Factor III), one would actually be measuring an extraverted $(\mathrm{I}+)$ form of conscientiousness. On the other hand, using ratings of careful, cautious, punctual, and formal (all III+I-) would assess an introverted ( $\mathrm{I}-$ ) form of conscientiousness. Johnson and Ostendorf (1993) suggest that such differences in secondary loadings in measures used by different research programs reflect differences in the way these programs conceptualize the five factors.

The Johnson and Ostendorf (1993) study was designed to reduce both the influence of theoretical predilections as well as random statistical fluctuations by computing composite $\mathrm{AB} 5 \mathrm{C}$ codes across four different sets of rating scales previously administered to nine American and six German samples (total $N=3433$ ). These analyses produced three 'factor-pure' $(\mathrm{V}+\mathrm{V}+)$ terms for the fifth factor: artistic, creative, 
and imaginative. The same three terms were identified as factor-pure by Hofstee et al. (1992), and Saucier (1992) suggested that the latter two define the core of Factor V. We suggested that creativity represents a point of agreement of Factor $\mathrm{V}$ across research programs.

Johnson and Ostendorf (1993) next looked at the overall composition of different rating scales for the Big Five by averaging the $\mathrm{AB} 5 \mathrm{C}$ depictions of the individual trait terms on each scale. Among rating scales for measuring Factor V, we found that the composite character of scales reflecting conventional intelligence represents the more constrained form of Factor V $(\mathrm{V}+\mathrm{III}+)$, called controlled intellect by Peabody and Goldberg (1989). Examples of V + III + terms include analytical, intellectual, intelligent, knowledgeable.

On the other hand, Factor $V$ scales interpreted as Openness to Experience appeared to reflect a more unconstrained cognitive style similar to what Peabody and Goldberg called expressive intellect. Lack of constraint or impulsivity is part of the low end of Factor III (constraint) and the high end of Factor I (Extraversion/Surgency) (Doddema-Winsemius and De Raad, 1993; Johnson and Ostendorf, 1993); therefore some traits on openness scales were identified as V+III - (changeable, unorthodox), and even more were identified as V + I + (e.g. experimenting, original, prefer variety). ${ }^{\prime}$

The foregoing analyses of the fifth factor are limited by their dependence on adjective ratings. McCrae (1990) suggests that the nature of the fifth factor might not be well represented by single-word trait descriptors. More elaborate questionnaires might be better suited for assessing the fifth factor. Saucier (1992) presents evidence that contradicts McCrae's (1990) suggestion. It may be prudent to withhold judgment about the nature of the fifth factor until AB5C analyses of personality questionnaires confirm or disconfirm the results of trait rating scales.

The remainder of this article presents new AB5C analyses of personality questionnaires relevant to the understanding of the fifth factor. The present analyses explore whether the subscales of NEO Openness and HPI Intellectance and School Success demonstrate a $\mathrm{V}+\mathrm{V}+, \mathrm{V}+\mathrm{III}+, \mathrm{V}+\mathrm{III}-$, or $\mathrm{V}+\mathrm{I}+$ character.

\section{An overview of the present study}

To ascertain the $\mathrm{AB} 5 \mathrm{C}$ character of the two questionnaires, with the first stage of the study I examined the loadings from separate factor analyses of the NEO and HPI subscales. This was done to allow an AB5C description of the subscales within the context of their own inventories. This strategy differs from the strategy of Costa and McCrae (1992b, 1994) of analyzing other inventories from the perspective of their own NEO or Wiggins and Broughton's (1991) mapping of other inventories within Wiggins's interpersonal circumplex, or even the AB5C analyses of Hofstee et al. (1992), which describe traits with respect to the carefully chosen markers of Goldberg (1992) for the Big Five. Given the differences between the ways research programs conceptualize and operationalize the Big Five (Johnson and Ostendorf, 1993) it would not be surprising to find that NEO Openness looks like an expressive

\footnotetext{
' If $\mathrm{V}+\mathrm{I}+$ and $\mathrm{V}+\mathrm{III}$ - both represent impulsive forms of Factor V, then symmetry suggests that both $\mathrm{V}+\mathrm{I}-$ and $\mathrm{V}+\mathrm{III}+$ would represent constrained forms of Factor V. The terms identified by Hofstee, De Raad and Goldberg (1992) as V + I- do indeed indicate thoughtful restraint: introspective, meditative, contemplating, and self-examining. However, the rating scales from Johnson and Ostendorf (1993) used in the present study contained no V+I- terms; therefore only V+III + terms were used to assess the constrained version of Factor $V$.
} 
form of Factor $V$ from the perspective of Goldberg's markers. More interesting would be the finding that the NEO Openness looks like an expressive form of Factor $\mathrm{V}$ from the perspective of the NEO factors themselves. The same reasoning applies to the HPI Intellectance and School Success scales.

In the second stage of the study, the NEO and HPI Factor V subscales are evaluated with a set of external AB5C markers: sets of trait terms previously identified (Johnson and Ostendorf, 1993) as possessing a $\mathrm{V}+\mathrm{V}+, \mathrm{V}+\mathrm{III}+, \mathrm{V}+\mathrm{III}-$, or $\mathrm{V}+\mathrm{I}+$ character. Because these trait terms represent the intersection of four major conceptions of the Factor $\mathrm{V}$, they provide a relatively theory neutral standard for evaluating the NEO and HPI Factor V subscales.

Finally, the results from the present study are compared to the interpretations of the NEO and HPI scale authors, to interpretations of others who have conducted research on Factor V, and to relevant-but neglected-research on creativity and cognitive style.

\section{METHOD}

\section{Subjects}

Subjects for the first stage of the research were two relatively large, diverse groups of adults who had completed either the NEO-PI-R or the revised HPI as part of studies of personality and job performance. Testing conditions and characteristics of the 1539 adults who took the NEO-PI-R are described by Costa, McCrae, and Dye (1991). Subjects I tested with the HPI included 516 persons (261 men, average age 36 years, and 255 women, average age 30 years) who participated in a study of job performance prediction for positions in a hardware store (cashier, floor clerk, truck driver; total $N=310$ ) and a bank (teller, sales representative, officer; total $N=206$ ). Of the hardware store subjects, 52 were incumbents and 258 were applicants. All of the bank subjects were incumbents. The applicants scored about one to two points ( $0.25-0.5 \mathrm{SD})$ higher than the incumbents on the Adjustment, Prudence, and Likeability scales; no other comparisons between incumbents and applicants showed statistically significant differences.

Subjects for the second stage of the research were 93 traditionally aged college students (58 male, 26 female, nine unknown) who completed the NEO-PI-R and a set of rating scales described below, and 30 college students (16 male, 14 female, average age 21 years) who completed the NEO-PI-R, the revised HPI and the rating scales.

\section{Measures}

\section{The revised NEO Personality Inventory (NEO-PI-R)}

The NEO contains five primary scales to assess the Big Five; each primary scale contains six subscales that Costa and McCrae (1992b, 1994) call facets. When the 30 facets are factor analyzed, five clear factors emerge, each defined by high loadings from six facets from the same scale (Costa et al., 1991). The facet scales Openness to Fantasy, Openness to Aesthetics, Openness to Feelings, Openness to Actions, Openness to Ideas, and Openness to Values (hereafter simply called Fantasy, Aesthe- 
tics, etc.) all load on the factor corresponding to Factor V of the FFM. Not surprisingly, McCrae and Costa refer to Factor $\mathrm{V}$ as Openness to Experience (McCrae and Costa, 1985).

\section{The Hogan Personality Inventory (HPI)}

From the beginning, development of the HPI was informed by the FFM (Hogan and Johnson, 1979, 1981), but Hogan (1986) actually followed more closely the measurement philosophy underlying its conceptual predecessor, the California Psychological Inventory (CPI; Gough, 1987). Like Gough, Hogan has been more concerned with the practical utility of his inventory than the factorial 'purity' of the measure. Consequently, a review of factor analyses of the HPI reveals a factor structure less clear-cut than that of the NEO.

The primary scales of the HPI are divided into subscales or homogeneous item composites (HICs). Hogan (1983) conducted a factor analysis of $45 \mathrm{HICs}$ from the prepublished version of the HPI and presented a seven-factor solution. In this analysis many HICs that were expected to tap Factor V actually showed appreciable loadings on two different factors, which Hogan called Intellectance A and Intellectance B. Three additional years of HPI research led Hogan to reduce the number of HICs from 45 to 43. For a new factor analysis of these 43 HICs, Hogan (1986) presents a six-factor solution in which many Intellectance HICs again load on two factors, which Hogan now called Creativity and School Success. In both analyses, the HICs Good Memory, School Success, and Math Ability all showed higher loadings on the Intellectance B or School Success factor.

In revising the HPI, Hogan and Hogan (1992) reduced the number of HICs to 41. They also formally recognized the dual nature of Factor $V$ by assigning Good Memory, School Success (renamed Education), Math Ability, and Reading to a new scale called School Success. The remaining HICs (Science Ability, Curiosity, Thrill-Seeking, Intellectual Games, Generates Ideas, and Culture) form the present Intellectance scale. School Success represents conventional, convergent thinking and Intellectance represents unconventional, divergent thinking.

\section{AB5C scales from the Inventory for Candid Trait Description}

The four trait rating inventories analyzed by Johnson and Ostendorf (1993) were combined into a single inventory labeled 'Inventory for Candid Trait Description' (ICTD; available from the author). They were arranged in the following order: (i) the 49-item Bipolar Adjective Rating Scales (BARS, Johnson, 1994a; Johnson, Germer, Efran and Overton, 1988); (ii) the 80 bipolar traits chosen by McCrae and Costa (1987) to represent the five dimensions assessed by the NEO; (iii) the 20 bipolar scale labels used by Norman (1963); and (iv) the 50-item Transparent Trait Rating Form (bipolar format) of Goldberg (1992), designed to reveal clearly that the inventory assesses the Big Five.

Subjects who described themselves with the ICTD were also described by two acquaintances, who returned the completed ICTD anonymously in a sealed envelope to the investigator. The general instructions to subjects and acquaintance raters stressed the need for honest, accurate appraisal and guaranteed confidentiality of the ratings. The instructions explained that the study was designed to assess agreement between self- and acquaintance descriptions for four inventories used in past research. The instructions also indicated that some terms will appear in more than one inventory 
because the scale authors borrowed ideas from each other, but that the format and ordering of terms varies across inventories.

From the 199 items on the ICTD, I created four 'AB5C rating scales' to assess different versions of Factor $V$. These scales were defined by items identified by Johnson and Ostendorf (1993) as either $\mathrm{V}+\mathrm{V}+$ (artistic, creative, imaginative), $\mathrm{V}+\mathrm{III}+$ (analytical, broad interests, cultured, curious, intellectual, intelligent, knowledgeable, perceptive, polished, and refined), V + III - (changeable and unorthodox), or V + I+ (experimenting, independent, liberal, original, prefer variety, sophisticated, and untraditional). For convenience of reference, I gave the scales labels based upon the ideas presented at the beginning of this article. The scale constructed from $\mathrm{V}+\mathrm{V}+$ items I called Creative Mentality; from V+III + items, Constrained Mentality; from V + III - items, Unconstrained Mentality; and V + I + items, Surgent Mentality. ${ }^{2}$

Alpha reliabilities were computed for the group of 93 students who completed the ICTD. Alpha reliabilities for self- and acquaintance ratings, respectively, for the Creative Mentality scale were 0.77 and 0.86 ; for the Constrained Mentality scale, 0.70 and 0.90 ; for the two-item Unconstrained Mentality scale, 0.51 and 0.62 ; and for the Surgent Mentality scale, 0.60 and 0.84 . Correlations between self- and acquaintance ratings for the four scales were, respectively, $0.55,0.35,0.56$, and 0.37 . In initial analyses, self- and acquaintance ratings showed similar correlations with the NEO and HPI subscales. To simply presentation, therefore, the two sources of ratings were averaged into a single rating score for all subsequent analyses.

\section{Analyses}

AB5C analysis of $N E O$

A FORTRAN program written by Ostendorf (Johnson and Ostendorf, 1993) was used to postmultiply the varimax-rotated matric of factor loadings of NEO facets given by Costa et al. (1991) by the submatrix described by Hofstee et al. (1992). For AB5C analyses, columns from a table of factor loadings are always rearranged to correspond to the order of factors described by Norman (1963). For the NEO, the column defined by high loadings from the Extraversion facets is labeled Factor I, for the Agreeableness facets, Factor II, for the Conscientiousness facets, Factor III, the Neuroticism facets, Factor IV, and the Openness to Experience facets, Factor $\mathrm{V}$.

Details of the AB5C analytic procedure are described by Hofstee et al. (1992) and by Johnson and Ostendorf (1993). Essentially, the FORTRAN program locates the factor loadings with the highest and second highest absolute magnitudes for each variable - in this case for each NEO facet scale. For example, the two largest loadings for the Openness to Fantasy facet were 0.58 on Factor $V$ and -0.31 on Factor III. The AB5C depiction for Fantasy is therefore $\mathrm{V}+\mathrm{III}-$. This depiction indicates that Fantasy represents primarily Openness to Experience and, secondarily, low Conscientiousness.

In cases where the primary loading is at least 3.73 times as large as the secondary

\footnotetext{
${ }^{2}$ Mentality (a term taken from Leone, 1973) is used here in the sense of cognitive style or mode of thought (Horton and Finnegan, 1973) rather than intelligence or intellectual ability. Whereas a low score on an IQ test is often interpreted quantitatively, as lack of intellectual ability, low or high scores on mentality reflect a predominant orientation toward one of two styles or modes of thinking (see Bakan, 1967; Conway, 1992; Maslow, 1957; Neisser, 1963; Tomkins, 1965; Werner, 1955).
} 
loading, the variable is depicted as a pure factor marker (see Hofstee et al. (1992, p. 147) for the rationale).

\section{AB5C analysis of HPI}

Although inspired and informed by the FFM, the HPI factor structure does not fit the FFM precisely. In fact, there are no published five-factor solutions for the HPI HICs. Hogan (1983) presents a seven-factor solution, whereas Hogan (1986) presents a six-factor solution. In the revised HPI manual, Hogan and Hogan (1992, p. 10) say "we concluded that there are about eight factors underlying the matrix (see Table 2.1).' None of these published factor analyses provides information such as eigenvalues or communalities.

The lack of definitive information on the factor structure of the HPI prompted me to conduct a series of exploratory analyses of the HIC scores of the employment sample $(N=516)$. A principal components analysis identified 11 eigenvalues greater than unity. The first seven eigenvalues were $6.38,4.78,2.33,1.96,1.85,1.49$, and 1.46 .

A scree test on eigenvalues indicates a two- or five-factor solution, but Goldberg and Digman (1994) advise against interpreting a two-factor solution. They suggest, instead, examining three- to seven-factor solutions in exploratory studies. I chose to examine the three, five, six, and seven-factor solutions. The usual AB5C analysis was conducted on the five-factor solution and the first five factors of the six-and seven-factor solutions. For the three-factor solution, the $\mathrm{AB} 5 \mathrm{C}$ algorithm was reduced to an ' $\mathrm{AB} 3 \mathrm{C}$ ' procedure, wherein two of the three factors themselves represented II + IV + and I + III - blends of the usual Big Five.

Composite AB5C codes for each HIC were calculated by determining the common or predominant themes across solutions (for details, see Johnson and Ostendorf, 1993). The result of the composite AB5C analysis of $\mathrm{HICs}$ is presented in Table 1.

\section{A $B 5 C$ rating scale correlations}

For the 92 subjects who had completed the NEO-PI-R, the creative, constrained, unconstrained, and surgent mentality rating scales were correlated with the Openness to Experience scale and its constituent facets. For the 30 subjects who had completed the HPI, the four mentality rating scales were correlated with Intellectance, School Success, and their constituent HICs.

\section{RESULTS}

\section{Internal AB5C analyses of the NEO and HPI}

Table 2 presents the AB5C facet assignments for the NEO and HPI subscales. Facet assignments are presented for all scales to give a complete picture of the AB5C analyses, but of particular interest are the results for the NEO Openness facet subscales and the HPI Intellectance and HPI School Success HIC subscales.

Of the six Openness facets, Aesthetics and Ideas are factor-pure $(\mathrm{V}+\mathrm{V}+)$, Fantasy and Values appear to be an unconstrained form of Factor $\mathrm{V}(\mathrm{V}+\mathrm{H}-)$, and Feelings and Actions seem to be extraverted/surgent forms of Factor $V(V+I+)$. This is 


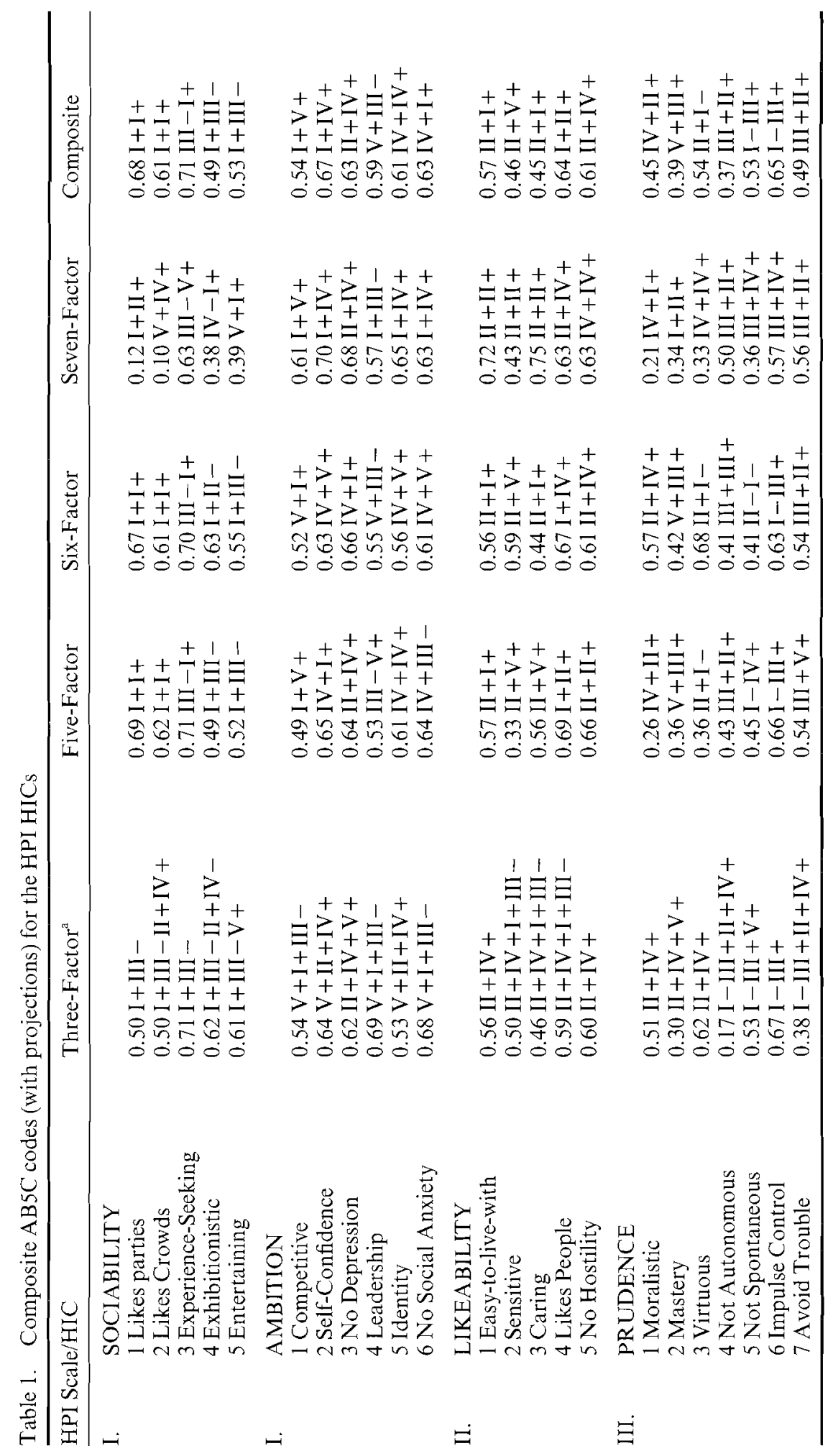




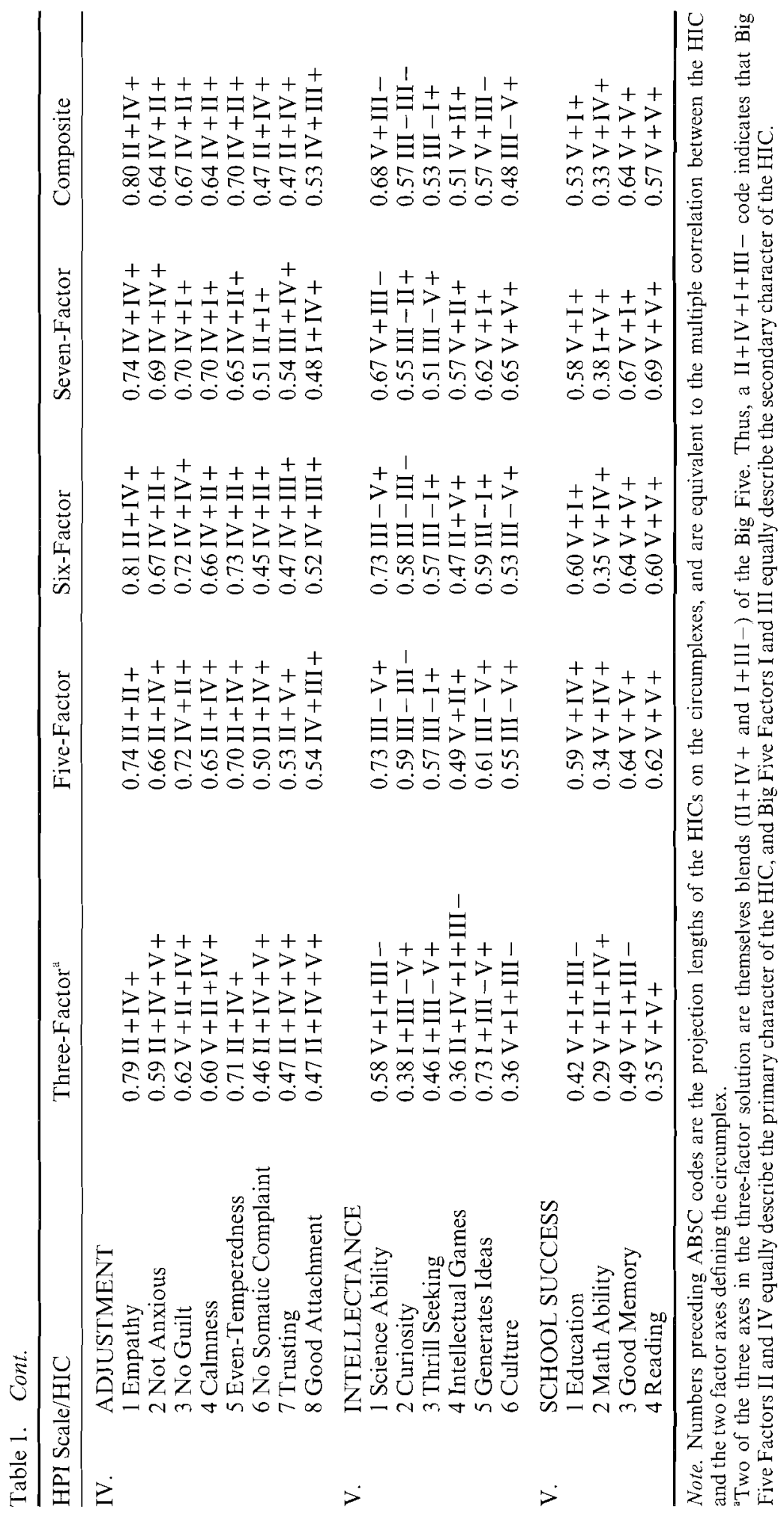


Table 2. Assignment of NEO and HPI Subscales to AB5C Facets (with projections)

\begin{tabular}{lll}
\hline NEO Scale & Projection & Facet \\
\hline Factor I & & \\
EXTRAVERSION & & \\
Warmth & 0.76 & I + II + \\
Gregariousness & 0.66 & I + IV+ \\
Assertiveness & 0.54 & I + III + \\
Activity & 0.68 & I+III+ \\
Excitement-Seeking & 0.69 & I+II - \\
Positive Emotions & 0.74 & I + I+
\end{tabular}

Factor II

\section{AGREEABLENESS}

Trust

Straightforwardness

Altruism

Compliance

Modesty

Tender-Mindedness

$\begin{array}{ll}0.66 & \text { II }+ \text { IV+ } \\ 0.71 & \text { II }+ \text { III }+ \\ 0.74 & \text { II }+ \text { I+ } \\ 0.77 & \text { II }+ \text { II+ } \\ 0.61 & \text { II }+ \text { IV- } \\ 0.67 & \text { II }+ \text { I+ }\end{array}$

Factor III

CONSCIENTIOUSNESS

$\begin{array}{lll}\text { Competence } & 0.76 & \text { III +IV+ } \\ \text { Order } & 0.70 & \text { III + V- } \\ \text { Dutifulness } & 0.73 & \text { III + II+ } \\ \text { Achievement Striving } & 0.76 & \text { III +I+ } \\ \text { Self-Discipline } & 0.82 & \text { III +IV+ } \\ \text { Deliberation } & 0.63 & \text { III +I- }\end{array}$

\section{SOCIABILITY}

SO1 Likes Parties

SO2 Likes Crowds

SO3 Experience-Seeking

SO4 Exhibitionistic

SO5 Entertaining

AMBITION

AM1 Competitive

AM2 Self-Confidence

AM3 No Depression

AM4 Leadership

AM5 Identity

AM6 No Social Anxiety

0.68

0.61

0.71

0.49

0.53

0.54

0.67

0.63

0.59

0.61

0.63

$\mathrm{I}+\mathrm{I}+$

$\mathrm{I}+\mathrm{I}+$

III-I+

I+ III -

I + III-

\section{LIKEABILITY}

LI1 Easy-to-live-with

LI2 Sensitive

LI3 Caring

LI4 Likes People

LI5 No Hostility

0.57

0.46

0.45

0.64

0.61

$\mathrm{I}+\mathrm{V}+$

$\mathrm{I}+\mathrm{IV}+$

II + IV +

$\mathrm{V}+\mathrm{III}-$

IV + IV +

IV $+\mathrm{I}+$

\section{PRUDENCE}

PR1 Moralistic

PR2 Mastery

PR3 Virtuous

PR4 Not Autonomous

PR 5 Not Spontaneous

PR6 Impulse Control

PR7 Avoid Trouble

$\begin{array}{ll}0.45 & \text { IV }+ \text { II }+ \\ 0.39 & \text { V+III+ } \\ 0.54 & \text { II }+ \text { I- } \\ 0.37 & \text { III }+ \text { II }+ \\ 0.53 & \text { I-III+ } \\ 0.65 & \text { I-II+ } \\ 0.49 & \text { III }+ \text { II + }\end{array}$

$\mathrm{II}+\mathrm{I}+$

$\mathrm{II}+\mathrm{V}+$

$\mathrm{II}+\mathrm{I}+$

$\mathrm{I}+\mathrm{II}+$

$\mathrm{II}+\mathrm{IV}+$ 
Table 2. Cont.

\begin{tabular}{|c|c|c|c|c|c|}
\hline NEO Scale & Projection & Facet & HPI Scale & Projection & Facet \\
\hline \multicolumn{6}{|l|}{ Factor IV } \\
\hline \multicolumn{3}{|l|}{ NEUROTICISM (inverted) } & \multicolumn{3}{|l|}{ ADJUSTMENT } \\
\hline Anxiety & 0.81 & $\mathrm{IV}+\mathrm{IV}+$ & ADl Empathy & 0.80 & $\mathrm{II}+\mathrm{IV}+$ \\
\hline Angry Hostility & 0.79 & $\mathrm{IV}+\mathrm{II}+$ & AD2 Not Anxious & 0.64 & $\mathrm{IV}+\mathrm{II}+$ \\
\hline Depression & 0.82 & IV +III+ & AD3 No Guilt & 0.67 & $\mathrm{IV}+\mathrm{II}+$ \\
\hline Self-Consciousness & 0.73 & $I V+I V+$ & AD4 Calmness & 0.64 & $\mathrm{IV}+\mathrm{II}+$ \\
\hline Impulsiveness & 0.60 & IV+I- & AD5 Even-Temperedness & 0.70 & IV + II + \\
\hline \multirow[t]{3}{*}{ Vulnerability } & 0.80 & IV +III+ & AD6 No Somatic Complaint & 0.47 & $\mathrm{II}+\mathrm{IV}+$ \\
\hline & & & AD7 Trusting & 0.47 & $\mathrm{II}+\mathrm{IV}+$ \\
\hline & & & AD8 Good Attachment & 0.53 & $\mathrm{IV}+\mathrm{III}+$ \\
\hline \multicolumn{6}{|l|}{ Factor $\mathrm{V}$} \\
\hline \multicolumn{3}{|l|}{ OPENNESS TO EXPERIENCE } & \multicolumn{3}{|l|}{ INTELLECTANCE } \\
\hline Fantasy & 0.66 & $\mathrm{~V}+\mathrm{III}-$ & INI Science Ability & 0.68 & $\mathrm{~V}+\mathrm{III}-$ \\
\hline Aesthetics & 0.73 & $V+V+$ & IN2 Curiosity & 0.57 & III - III- \\
\hline Feelings & 0.64 & $V+I+$ & IN3 Thrill Seeking & 0.53 & $\mathrm{III}-\mathrm{I}+$ \\
\hline Actions & 0.60 & $\mathrm{~V}+\mathrm{I}+$ & IN4 Intellectual Games & 0.51 & $\mathrm{~V}+\mathrm{II}+$ \\
\hline Ideas & 0.75 & $V+V+$ & IN5 Generates Ideas & 0.57 & $\mathrm{~V}+\mathrm{III}-$ \\
\hline \multirow[t]{6}{*}{ Values } & 0.50 & $\mathrm{~V}+\mathrm{III}-$ & IN6 Culture & 0.48 & $\mathrm{III}-\mathrm{V}+$ \\
\hline & & & \multicolumn{3}{|l|}{ SCHOOL SUCCESS } \\
\hline & & & SCl Education & 0.53 & $V+I+$ \\
\hline & & & SC2 Math Ability & 0.33 & $\mathrm{~V}+\mathrm{IV}+$ \\
\hline & & & SC3 Good Memory & 0.64 & $\mathrm{~V}+\mathrm{V}+$ \\
\hline & & & SC4 Reading & 0.57 & $\mathrm{~V}+\mathrm{V}+$ \\
\hline
\end{tabular}


consistent with our previous suggestion that Openness to Experience is a $\mathrm{V}+\mathrm{III}-$ or $\mathrm{V}+\mathrm{I}+$ blend (Johnson and Ostendorf, 1993).

The HICs within the two Factor V scales on the HPI (Intellectance and School Success) occupy conspicuously different locations within the abridged circumplex. Three of the six Intellectance HICs actually load primarily (and negatively) on Factor III rather than Factor V, and two have secondary negative loadings on Factor III. This means that these HICs, Curiosity (III-III -), Culture (III-V +), Thrill-Seeking $(\mathrm{III}-\mathrm{I}+$ ), and Science Ability and Generates Ideas (both $\mathrm{V}+\mathrm{III}-$ ) reflect lack of constraint. On the other hand, all four School Success HICs load primarily on the fifth factor, and two of them (Good Memory and Reading) are factor-pure. These findings support Hogan and Hogan's (1992) decision to split the original Intellectance scale (Hogan, 1986) into Intellectance and School Success. The lack of constraint theme tapped by the current Intellectance scale places this scale closer in meaning to openness than the School Success scale, which seems to represent a more stable form of intellectual activity.

\section{Relationships between NEO facets, HPI HICs, and AB5C Rating Scales}

The correlations between the four AB5C rating scales and the NEO facets and HPI HICs are reported in Table 3. The overall NEO Openness to Experience scale correlated substantially with the Creative Mentality $(V+V+)$ scale, the Surgent Mentality $(\mathrm{V}+\mathrm{I}+)$ scale, and the Unconstrained Mentality $(\mathrm{V}+\mathrm{III}-)$ scale. These external correlations, like the previous internal AB5C analysis, support Johnson and Ostendorf's interpretation of Openness as an unconstrained or surgent form of mentality.

Aesthetics and Ideas, the two facets that appeared to represent a factor pure $(\mathrm{V}+\mathrm{V}+)$ form of the fifth factor in the internal AB5C analysis, in fact correlated higher than any other facet with the Creative Mentality $(V+V+)$ scale. In addition, these facets correlated significantly with both Unconstrained and Surgent Mentality, attesting to their centrality in the Openness scale. Fantasy, Feelings, and Actions, on the other hand, showed barely significant correlations with Creative Mentality, and Values, only a small correlation with Surgent Mentality. The notion that Ideas and Aesthetics form the core of Openness is outlined in more detail in the Discussion section below. But, first, I shall briefly summarize the results for the two HPI scales, Intellectance and School Success.

The lack of relationships between the Intellectance and either the V+III- or $\mathrm{V}+\mathrm{I}+$ ratings disconfirms the hypothesis generated from the internal AB5C analysis-namely, that Intellectance, like Openness to Experience, represents a form of Unconstrained or Surgent Mentality. Overall Intellectance and overall School Success actually showed significant correlations with the Constrained Mentality $(\mathrm{V}+\mathrm{III}+)$ ratings. Unsurprising is the $\mathrm{V}+\mathrm{III}+$ characterization of School Success, which is consistent with the current internal $\mathrm{AB} 5 \mathrm{C}$ analysis and with an earlier prediction by Johnson and Ostendorf (1993). The Education and Reading HICs appear to be the main contributors to a Constrained Mentality orientation of the School Success scale.

The overall Intellectance scale also correlates significantly with the Creative Mentality $(\mathrm{V}+\mathrm{V}+)$ ratings. The specific HICs responsible for this correlation are Generates Ideas and Culture. Table 4, which shows the correlations between NEO facets and HPI HICs, indicates that these two HICs correspond most closely to Openness to 
Table 3. AB5C rating scale correlates of NEO facets and HPI HICs

\begin{tabular}{|c|c|c|c|c|}
\hline \multirow[b]{2}{*}{ NEO and HPI scales } & \multicolumn{4}{|c|}{ AB5C Rating Scales } \\
\hline & $\begin{array}{l}\text { Creative } \\
(\mathrm{V}+\mathrm{V}+)\end{array}$ & $\begin{array}{l}\text { Constrained } \\
(\mathrm{V}+\mathrm{III}+)\end{array}$ & $\begin{array}{c}\text { Uncon- } \\
\text { strained } \\
(\mathrm{V}+\mathrm{III} \sim)\end{array}$ & $\begin{array}{l}\text { Surgent } \\
(\mathrm{V}+\mathrm{I}+)\end{array}$ \\
\hline \multicolumn{5}{|l|}{ NEO-PI-R $(N=92)$} \\
\hline Openness to Experience & $0.52 * *$ & 0.22 & $0.44 * *$ & $0.52 * *$ \\
\hline Fantasy & $0.24 *$ & 0.05 & 0.19 & 0.20 \\
\hline Aesthetics & $0.44 * *$ & 0.15 & $0.38 * *$ & $0.47 * *$ \\
\hline Feelings & $0.25^{*}$ & 0.11 & 0.08 & 0.16 \\
\hline Actions & $0.24 *$ & 0.19 & $0.47 * *$ & $0.38 * *$ \\
\hline Ideas & $0.61 * *$ & $0.26^{*}$ & $0.30 * *$ & $0.33 * *$ \\
\hline Values & -0.09 & 0.09 & 0.16 & $0.25^{*}$ \\
\hline \multicolumn{5}{|l|}{$\operatorname{HPI}(N=30)$} \\
\hline Intellectance & $0.59 * *$ & $0.51 * *$ & 0.24 & 0.34 \\
\hline Science Ability & 0.21 & 0.32 & 0.03 & 0.13 \\
\hline Curiosity & 0.22 & 0.21 & -0.12 & 0.07 \\
\hline Thrill-Seeking & 0.29 & $0.45^{*}$ & 0.07 & 0.30 \\
\hline Intellectual Games & 0.04 & -0.21 & 0.27 & 0.05 \\
\hline Generates Ideas & $0.55 * *$ & $0.62 * *$ & $0.36^{*}$ & $0.43 *$ \\
\hline Culture & $0.50 * *$ & -0.03 & 0.09 & -0.07 \\
\hline School Success & 0.34 & $0.52 * *$ & 0.21 & $0.38 *$ \\
\hline Education & 0.12 & $0.38 *$ & 0.13 & 0.11 \\
\hline Math Ability & 0.00 & 0.20 & 0.17 & 0.23 \\
\hline Good Memory & 0.20 & 0.33 & 0.02 & 0.19 \\
\hline Reading & $0.47 * *$ & $0.37 *$ & 0.19 & 0.34 \\
\hline
\end{tabular}

Ideas and Aesthetics - precisely the two facets that appeared to represent the $\mathrm{V}+\mathrm{V}+$ core of Openness to Experience.

\section{DISCUSSION}

This study began with the questions: (i) How can we account for differences of opinion about Factor V? and (ii) What is the 'best' conception of Factor V? The answer to the first question is that different opinions about Factor $V$ derive from scales containing dissimilar proportions of Creative Mentality $(\mathrm{V}+\mathrm{V}+$ ), Constrained Mentality (V+III+), Unconstrained Mentality (V+III-), and Surgent Mentality $(\mathrm{V}+\mathrm{I}+)$. The Openness to Experience scale clearly contains Creative, Unconstrained, and Surgent facets. The Intellectance scale, on the other hand, does not assess Surgent Mentality. It is easy to see how a researcher committed to using the Openness to Experience scale might regard the Intellectance scale as an incomplete measure of Factor V.

Given the various forms of the fifth factor, how does one decide upon the 'best' conception of Factor V? Researchers committed to a particular scale might answer this question operationally by assuming that the Factor $\mathrm{V}$ domain is what their preferred scale measures. This is because psychologists devote considerable time and energy into scale development and validation and therefore often allow their scale's properties to dictate their understanding of the domain tapped by the scale (Wicklund, 1990). From this point of view, the strategy for elucidating the Factor 
Table 4. Correlation Matrix of NEO Facets and HPI HICs $(N=30)$

\begin{tabular}{|c|c|c|c|c|c|c|c|}
\hline & \multirow{2}{*}{$\begin{array}{c}\text { Total } \\
\text { Openness }\end{array}$} & \multicolumn{6}{|c|}{ Openness Facets } \\
\hline & & Fantasy & Aesthetics & Feelings & Actions & Ideas & Values \\
\hline Intellectance & $0.39 *$ & 0.05 & 0.15 & 0.18 & -0.09 & $0.64 * *$ & 0.28 \\
\hline Science Ability & 0.20 & -0.20 & 0.10 & 0.04 & -0.22 & $0.66 * *$ & 0.12 \\
\hline Curiosity & 0.07 & -0.11 & -0.07 & 0.02 & -0.09 & $0.43 *$ & -0.04 \\
\hline Thrill-Seeking & 0.08 & 0.04 & -0.10 & 0.03 & 0.01 & -0.01 & 0.32 \\
\hline Intellectual Games & 0.12 & 0.10 & -0.15 & 0.12 & -0.09 & 0.33 & 0.05 \\
\hline Generates Ideas & 0.34 & 0.01 & 0.13 & 0.05 & 0.02 & $0.59 * *$ & 0.25 \\
\hline Culture & $0.43 *$ & 0.29 & $0.55^{*}$ & 0.35 & 0.05 & 0.23 & 0.00 \\
\hline School Success & 0.29 & 0.14 & 0.09 & -0.02 & 0.07 & $0.41 *$ & 0.25 \\
\hline Education & -0.03 & -0.02 & -0.17 & -0.24 & 0.01 & 0.10 & 0.16 \\
\hline Math Ability & 0.28 & 0.16 & -0.07 & 0.16 & $0.42 *$ & 0.09 & 0.33 \\
\hline Good Memory & 0.09 & -0.08 & 0.05 & -0.14 & -0.14 & $0.41 *$ & 0.06 \\
\hline Reading & 0.32 & 0.24 & 0.34 & 0.12 & -0.11 & 0.34 & 0.06 \\
\hline
\end{tabular}


$\mathrm{V}$ domain becomes the traditional task of establishing the construct validity of the scale.

An alternative strategy, employed in the present study, holds that the best conception of Factor $\mathrm{V}$ might be found where different measures intersect or converge (Johnson and Ostendorf, 1993). This strategy assumes that any scale meant to represent Factor $V$ actually assesses two components. One component is the understanding of the Factor $\mathrm{V}$ domain shared by many researchers; this area is represented by the overlap between the Openness to Experience and Intellect circles in Figure 1 of McCrae (1994). The other component is the scale developer's idiosyncratic view of this domain. This is represented by the non-overlapping areas in McCrae's Figure 1.

The difference between our shared and idiosyncratic views of the domain is analogous to the basic psychometric distinction between common and unique variance. Just as we compute the average for a set of ratings to remove idiosyncratic error to obtain the 'true score' (Hofstee, 1994), we can factor analyze a set of Factor $\mathrm{V}$ scales to reach a shared understanding of the domain (Trapnell, 1992). The AB5C approach merely takes standard factor analysis one step further: it attempts to account for the apparently unique variance in terms of the remaining four factors. ${ }^{3}$

I am not suggesting here that the best conception of Factor $\mathrm{V}$ is necessarily a compromise between alternative views. After all, the modern theory of combustion is not a compromise between phlogiston theory and Lavoisier's ideas. However, until one view of Factor V becomes as dominant in psychology as Lavoisier's oxygen theory did in chemistry, I suggest that we define Factor $V$ as the area of convergence or overlap across measures.

Previously (Johnson and Ostendorf, 1993), I suggested that trait terms found to be 'factor-pure' $(\mathrm{V}+\mathrm{V}+)$ across different measures represent the core meaning of Factor $\mathrm{V}$. These terms were artistic, creative, and imaginative. In the present study, I hypothesized that a major point of convergence between the NEO and HPI would be through their factor-pure $(\mathrm{V}+\mathrm{V}+)$ subscales. The next section highlights how $\mathrm{V}+\mathrm{V}+$ subscales behave differently from non-pure subscales, and the section following the next discusses why the $\mathrm{V}+\mathrm{V}+$ scales appear to be more 'central' than the peripheral V/I and V/III blends. Because the AB5C analyses produced more consistent results for the NEO than for the HPI, the remainder of the discussion will focus more on the Openness facets than on the Intellectance and School Success HICs.

\section{Factor-pure versus impulsive blends of Openness to Experience}

The initial, internal A B5C analyses of Openness facets indicate that, from the perspective of the NEO-PI-R, Openness to Aesthetics and Openness to Ideas represent the 'core meaning' $(\mathrm{V}+\mathrm{V}+$ ) of Factor V. Openness to Feelings and Openness to Action appear to represent an impulsively extraverted or 'Surgent' $(\mathrm{V}+\mathrm{I}+$; see Norman, 1963) form of Factor V. Openness to Fantasy and Openness to Values, on the other hand, are impulsively unconstrained $(\mathrm{V}+\mathrm{III}-$ ) versions of the fifth factor. The more

"I do not claim that the AB5C model accounts for all important variance in terms of the five factors; this would be contrary to the data indicating that the NEO facets capture valid unique variance beyond what can be accounted for by the five broad factors (McCrae and Costa, 1992). Nonetheless, judging from similar, previous research (Reynolds and Nichols, 1977), I would hypothesize that most of the variance in any prediction study can be accounted for by common factor variance rather than unique variance. 
impulsive varieties of Openness are discussed immediately below before returning to the Ideas and Aesthetics facets, which seem more central to the core of Factor V.

\section{External correlates of impulsive openness}

McCrae and Costa (1992) found that, among 305 persons who completed Gough and Heilbrun's (1983) Adjective Check List (ACL), persons with high scores on the NEO Feelings or Action facets tended to check the term talkative more often than persons who scored low on these facets. This finding supports the idea that these facets represent extraverted forms of the fifth factor $(V+I+)$. In the present study, Openness to Action correlated with both the $\mathrm{V}+\mathrm{I}+$ trait scale (experimenting, liberal, untraditional, etc.) and the V+III - trait scale (changeable, unorthodox), but Openness to Feelings failed to correlate with either of these scales.

On the other hand, high scorers on Fantasy tended to describe themselves with the ACL terms humorous and mischievous, and high-scorers on Values described themselves as unconventional and firtatious (McCrae and Costa, 1992). These terms suggest a slightly more immodest or perhaps even risque form of the fifth dimension $(\mathrm{V}+\mathrm{III}-)$. In the present study, Fantasy failed to correlate with either the $\mathrm{V}+\mathrm{I}+$ or $\mathrm{V}+\mathrm{III}-$ trait scales, but Values correlated with the $\mathrm{V}+\mathrm{I}+$ trait scale.

In summary, initial AB5C analyses of NEO Openness facet intercorrelations suggest that Openness to Action, Feelings, Fantasy, and Values represent impulsive $(\mathrm{I}+$ or III -$)$ versions of the fifth factor. Subsequent comparisons of these four facets with scales consisting of unconstrained $(\mathrm{V}+\mathrm{III}-)$ or surgent $(\mathrm{V}+\mathrm{I}+)$ trait terms from the $\mathrm{AB} 5 \mathrm{C}$ model confirm the impulsive character of Action and Values, but not Fantasy or Feelings. This latter finding is more consistent with earlier factor analyses (Glisky, Tataryn, Tobias and Kihlstrom, 1991; Trapnell, 1992) suggesting that Openness to Action and Values reflect unconventional (III-) behavior. Fantasy and Feelings, on the other hand, together help define absorption (Tellegen, 1994; Tellegen and Atkinson, 1974). Whereas Action and Values reflect unconventional behavior, Fantasy and Feelings represent openness to unconventional, unusual thought processes, or what others have called low ego control (Block and Block, 1980; Johnson, 1983; Laufer, Johnson and Hogan, 1981).

\section{The primacy offactor-pure Openness to Experience}

Correlations between the NEO Openness facets and the Creative $(\mathrm{V}+\mathrm{V}+)$, Constrained $(\mathrm{V}+\mathrm{III}+)$, Unconstrained $(\mathrm{V}+\mathrm{III}-)$, and Surgent $(\mathrm{V}+\mathrm{I}+)$ Mentality ratings affirm the centrality of the Ideas and Aesthetics facets in two ways. First, Ideas and Aesthetics show much stronger correlations with the $\mathrm{V}+\mathrm{V}+$ ratings than any other Openness facet. In addition, both also correlated significantly with the V+ III and $\mathrm{V}+\mathrm{I}+$ trait scales. The intersection of the Ideas and Aesthetics facets with scales representing three different Factor $V$ variants (Creative, Unconstrained, and Surgent) testifies to the centrality of these facets to the fifth factor.

The primacy of Ideas and Aesthetics is further demonstrated by their unique association with alternative measures of Factor $V$ in this and other studies. In this study, they were the only facets to correlate with HICs from the HPI Intellectance scale. They were also the only two Openness facets found to correlate with Goldberg's (1992) measure of Factor V (Costa and McCrae, 1992a). If the core of Factor V 
is what different measures of Factor $\mathrm{V}$ have in common (Johnson and Ostendorf, 1993), then the Creative Mentality facets, Openness to Ideas and Openness to Aesthetics, appear to form that core.

The group that completed both the NEO and HPI in the present study was considered too small to conduct a factor analysis of the facets/HIC matrix in Table 4, but a previous factor analysis of NEO facets and HPI HICs by Trapnell (1992) again underscores the cardinal nature of Ideas and Aesthetics. Trapnell interpreted a three-factor varimax solution; Aesthetics showed the highest loading on the first factor, which also contained an appreciable loading from Ideas. This factor, also defined by an appreciable loading from the Culture HIC, Trapnell called Absorption. The second factor, defined partly by a significant loading from the Generates Ideas HIC as well as Openness to Ideas, Trapnell called Intellectance. ${ }^{4}$

Trapnell (1992) suggests that Intellectance and Absorption are the most important subdomains of Factor V. I agree that these two subdomains form the heart of Factor $\mathrm{V}$; I would further suggest that Openness to Ideas and Openness to Aesthetics lie at the heart of the two subdomains. Trapnell also correctly points out that the two subdomains are related to the Investigative and Artistic scales in the hexagonal model of vocational personalities of Holland (1985a). The relationship between openness to experience and Holland's hexagonal model was noted by Johnson and Hogan (1981), later investigated by Johnson (1983), and finally studied in detail by Costa, McCrae, and Holland (1984). Trapnell has done a superb job elaborating upon this earlier work, but both he and the other authors fail to acknowledge clearly the work of the individual who first noticed the relationship between Factor $\mathrm{V}$ and Holland's typology - George Welsh (1975). This article concludes the discussion of the primacy of the $\mathrm{V}+\mathrm{V}+$ Ideas and Aesthetics facets by proposing a synthesis with the work of Welsh and other underacknowledged researchers.

\section{A grand(iose) synthesis: veritas et pulchro}

Within discussions of Factor V, surprisingly little reference is made to Welsh (1975, 1977, 1980), who coined the term Intellectence (spelled with an 'e'). Hogan and Johnson (1979, 1981) and Hogan and Hogan (1992) cite Welsh as the source of their homophonic synonym, Intellectance (spelled with an 'a') but do not discuss Welsh's ideas. Piedmont, McCrae and Costa (1991) seemingly dismiss Welsh's work when they say 'Welsh's (1975) origence-intellectance (sic) theory may not fit within the five-factor model' (p. 631) and '[unexpected correlations in their study] call into question the validity of some of Welsh's scales' (p. 636). Trapnell (1992), Saucier (1992), and McCrae (1987) do not cite Welsh in their discussions of Factor V.

Welsh's method of scale construction followed the Minnesota tradition that produced inventories such as the CPI (Gough, 1987) and MMPI (Hathaway and McKinley, 1967). Scale authors who follow today's factor analytic methods often find the Minnesota tradition aesthetically displeasing, and therefore reject such methods as personally distasteful (Johnson, 1994b). Welsh's methods are not only unfashionable, but too complex to describe fully here. The following is a simplified description; those interested in the details can consult Welsh (1975).

\footnotetext{
${ }^{4}$ Their third factor, Traditionalism, defined by negative loadings from Openness to Actions and Values, appears to be an inverted form of unconstrained $(\mathrm{V}+\mathrm{III}-$ ) Openness.
} 
Welsh (1975) developed two orthogonal personality scales by identifying items from the Strong Vocational Interest Blank (SVIB; Strong, 1959), MMPI (Hathaway and McKinley, 1967), and Adjective Check List (ACL; Gough and Heilbrun, 1965) differentially endorsed by persons who scored very high or very low on a standardized intelligence test and a standardized figure preference scale. Items that distinguished high and low-scorers on the intelligence test formed a dimension he called Intellectence. Items that distinguished those who prefer complex, asymmetric figure drawings over simple, symmetric drawings formed a dimension he called Origence.

Through construct validation of his scales, Welsh clarified the personality traits of those who scored toward the extremes of Intellectence or Origence. Low-intellectent individuals immerse or engage themselves in immediate, concrete experiences and relationships with others. High-intellectent individuals disengage and distance themselves from others, preferring to relate to the world indirectly through abstract symbols. Low-origent persons feel more comfortable in conventional situations where formal, explicit, externally imposed rules govern behavior and social interaction. High-origent persons feel more comfortable in unstructured situations where they are free to transcend ordinary formalities to create more subtle, implicit orders.

Because the Intellectence and Origence scales were built partially from vocational interest items, Welsh (1977) was able to relate the scales to Holland's hexagonal model of vocational personalities. In 1979, I used the data presented in Table 9.6 of Welsh's (1977) chapter to actually plot the Intellectence and Origence dimensions onto the hexagon (Hogan and Johnson, 1979); that diagram is reproduced in Figure 1.

Like Trapnell (1992), I found it useful to diagram the hexagon within a circle and to insert midpoints between the six corners of the hexagon. Holland (1985b, p. 13) himself has acknowledged the importance of the areas between the points of the hexagon. Trapnell chose to insert two intermediate values to form a circumplex divided into octants, similar to the Interpersonal Circumplex (Wiggins, 1979). Unintentionally anticipating the AB5C model (Hofstee et al., 1992), I inserted intermediate values between all six points of the hexagon, dividing the circle into duodecants. However, rather than following the circumplex tradition of drawing axes through the midpoint of the circle, I found it more heuristically useful to plot the Intellectence dimension through the points anchored by the Investigative personality and the midpoint between the Enterprising and Social personalities (see Figure 1). This alignment matches Trapnell's (1992, Figure 4) placement of Intellectance on his Holland octagon. I drew Origence through the Artistic point and the midpoint between the Convention and Realistic personalities. This plot is very similar to Trapnell's placement of Absorption in his own diagram.

The Intellectence-Origence dimensions divide the circle into four areas that describe four cognitive personality styles that Welsh (1980) calls Imaginative (high Origence, low Intellectence), Intuitive (high Origence, high Intellectence), Industrious (low Origence, low Intellectence), and Intellective (low Origence, high Intellectence). Welsh $(1975,1980)$ argues that genuine creativity is found in the Intuitive quadrantthat is, in the area between the Investigative and Artistic vocational interests. Trapnell (1992) notes that overall Openness to Experience corresponds to the InvestigativeArtistic area. He further suggests that the poetry items on the Openness to Experience scale that dominate the first unrotated factor of all Openness items represents 'the middle ground of reason (I) and aesthetics (A), the synthesis of truth and beauty 


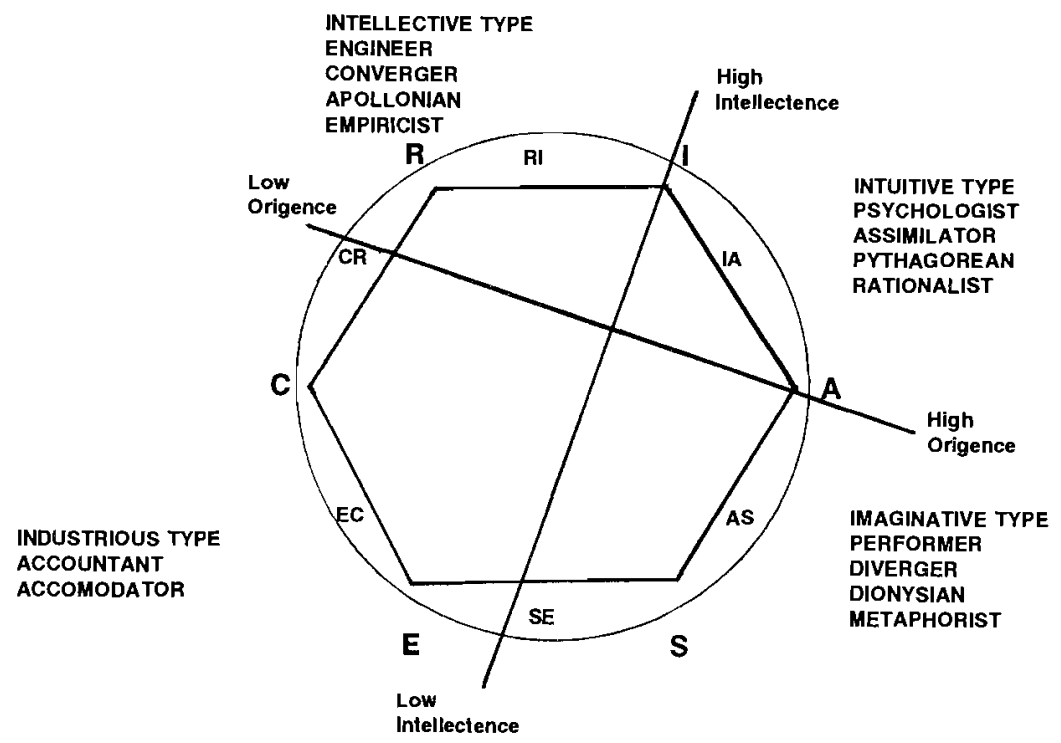

Figure 1. A grand synthesis of cognitive styles and personality types, adapted from Hogan and Johnson (1979). The first label in each set of descriptions refers to the personality types proposed by Welsh (1980), the second, examples of each vocational type proposed by Holland (1985b), the third, the learning styles proposed by Kolb (1976), the fourth, the forms of aesthetic imagery proposed by Knapp (1964), and the fifth, the epistemological styles proposed by Royce (1964). Note that no aesthetic imagery or epistemological style label was offered for the underappreciated Industrious type, although Royce (1964) initially used the label 'Authoritarian' before dropping it.

that so captivates and motivates the epistemically curious' (p. 6). Perhaps the Intellectence/Origence, Investigative/Artistic, Ideas/Aesthetics synthesis that describes the creative core of Factor $\mathrm{V}$ deserves the motto: veritas et pulchro.

\section{Two reservations and a hypothesis}

I have two reservations about the model proposed here. The first is that the model suggests that the creative core of Factor $\mathrm{V}$ lies between the negative poles of Factors I and III, but the data of Costa and McCrae indicate that Factor V is orthogonal to Factors I and III. I have no answer to this problem at the present time except to note that one should not always let data get in the way of a good idea. The second problem concerns the potential self-serving nature of the model for psychologists. The remainder of the article explains why the model may be self-serving.

Many fourfold typologies of personality have been proposed since the time of the ancient Greeks, and numerous authors have suggested that these typologies are close variants of each other (Hogan, 1983; Johnson, 1983; Martindale and Martindale, 1988). For illustrative purposes, Figure 1 diagrams correspondences between the personality typologies proposed by Welsh (1980) and Holland (1985a) and similar typologies for learning styles (Kolb, 1976), imagery (Knapp, 1964), and epistemological style (Royce, 1964).

The perennial re-invention of this typological wheel from the times of ancient astrologers (Kemp, 1988; Musès, 1972) and Sufi mystics (Keen, 1973) to modern-day 
interpersonal theorists (Wiggins, 1979) testifies to the appeal of the circular model. Yet, popular appeal hardly guarantees scientific validity. Both McCrae (1990) and Block (1994) urge us to take personality psychology beyond the realm of folk psychology and common-sense. I agree, and will end with a hypothesis that attempts to link the domain of Factor $\mathrm{V}$ with evolutionary biology and neurophysiology.

Psychologists, who are Investigative-Artistic types sometimes appear to be selfadulating in their focus on the Intuitive quadrant of the circle (Figure 1). To me, a particularly embarrassing example of such self-adulation is Maslow's hierarchy of needs (see Samuel, 1981, Figure 3-1 on p. 90). The hierarchical ordering implies a superiority of self-actualization needs over basic needs, but there is a clear correspondence between Maslow's needs and Holland's vocational personalities. Realistic types are concerned with physiological survival, Conventional types, with safety, Social types, with belongingness, and Enterprising types, with esteem. At the top of the pyramid in Samuel's (1981) figure sits self-actualization, with arrows pointing toward the pursuit of knowledge (veritas, an Investigative concern) and appreciation of beauty (pulchro, an Artistic concern).

Although Investigative and Artistic personality traits are related to status (Kelso, 1976), which is, in turn, related to reproductive success (Hogan, 1983), I cannot help but wonder about the elitist implications of the hierarchical pyramid. The circular arrangement of types suggests that all types play an indispensable role in human groups (Johnson, 1983), and I have found in my vocational research that low creativity is associated with superior performance in occupations in the Industrious quadrant (Johnson, 1990).

The circular model seems to accommodate recent thinking about evolution and personality (Buss, 1991; MacDonald, 1991, 1994), which suggests that individual differences in personality represent alternative strategies for adaptively exploiting the environment. Every ambiguous, novel situation could be either a source of benefit or harm, and therefore all mammals seem to show individual differences in the tendency to investigate or evade such situations (Zuckerman, 1990). Approach and avoidance appear to be governed by independent neurological systems (Gray, 1982), which has led to the use of the terms 'go system' and 'stop system' (MacDonald, 1991). My hypothesis is that we perceive the 'go system' as Extraversion/Surgency, or Factor I, and the 'stop system' as Constraint, or Factor III, and that Factor $\mathrm{V}$, Creativity, accompanies both disengagement (I-) and lack of constraint (III-). For those with laboratories for biopsychological assessment of personality (Haier et al., 1980, 1987; Makarec and Persinger, 1985, 1990; Zuckerman, 1989) this hypothesis seems easily testable.

\section{ACKNOWLEDGEMENTS}

This research is a direct outgrowth of work conducted as a visiting research fellow at Universität Bielefeld, Bielefeld, Germany, supported by a fellowship from the Alexander von Humboldt-Stiftung. Gratitude is expressed to Alois Angleitner and Robert Wicklund for helping to arrange my stay and to the psychology department at Bielefeld and the von Humboldt-Stiftung for their support. I would also like to thank the editors of this Special Issue and Jeff McCrae for their comments on an earlier version of this manuscript. 


\section{REFERENCES}

Bakan, D. (1967). On Method: Toward a Reconstruction of Psychological Investigation, JosseyBass, San Francisco, CA.

Block, J. (1994). 'A contrarian view of the five factor approach to personality description', Psychological Bulletin, in press.

Block, J. H. and Block, J. (1980). 'The role of ego-control and ego-resiliency in the organization of behavior'. In: Collins, W. A. (Ed), The Minnesota Symposia on Child Psychology, Vol. 13, pp. 39-101, Erlbaum, Hillsdale, NJ.

Buss, D. M. (1991). 'Evolutionary personality psychology', Annual Review of Psychology, 42: 459-491.

Conway, J. B. (1992). 'A world of difference among psychologists', Canadian Psychology/ Psychologie Canadienne, 33: 1-24.

Costa, P. T., Jr, and McCrae, R. R. (1992a). 'Comparability of alternative measures of the five-factor model in peer ratings', paper presented at the Annual Convention of the American Psychological Society, San Diego, CA, 20-22 June, 1992.

Costa, P. T. Jr. and McCrae, R. R. (1992b). Revised NEO Personality Inventory (NEO-PI-R) and NEO Five-Factor Inventory (NEO-FFI): Professional Manual, Psychological Assessment Resources, Odessa, FL.

Costa, P. T., Jr. and McCrae, R. R. (1994). 'Domains and facets: hierarchical personality assessment using the revised NEO Personality Inventory', Journal of Personality Assessment, in press.

Costa, P. T., Jr., McCrae, R. R. and Dye, D. A. (1991). 'Facet scales for Agreeableness and Conscientiousness: a revision of the NEO Personality Inventory', Personality and Individual Differences, 12: 887-898.

Costa, P. T., Jr., McCrae, R. R. and Holland, J. L. (1984). 'Personality and vocational interests in an adult sample', Journal of Applied Psychology, 69: 390-400.

Digman, J. M. (1990). 'Personality structure: emergence of the Five-Factor Model', Annual Review of Psychology, 41: 417-440.

Doddema-Winsemius, M. and De Raad, B. (1993). 'Factors in teacher's ratings of schoolchildren: Heymans' data reconstructed by modern standards', European Journal of Personality, 7: 283-298.

Glisky, M. L., Tataryn, D. J., Tobias, B. A. and Kihlstrom, J. F. (1991). 'Absorption, openness to experience, and hypnotizability', Journal of Personality and Social Psychology, 60: 263272.

Goldberg, L. R. (1992). 'The development of markers for the Big-Five factor structure', Psychological Assessment, 1: 26-42.

Goldberg, L. R. and Digman, J. M. (1994). 'Revealing structure in the data: principles of exploratory factor analysis'. In: Strack, S. and Lorr, M. (Eds), Differentiating Normal and Abnormal Personality, Springer, New York, in press.

Gough, H. G. (1987). California Psychological Inventory Administrator's Guide, Consulting Psychologists, Palo Alto, CA.

Gough, H. G. and Heilbrun, A. B. (1965). The Adjective Check List Manual, Consulting Psychologists, Palo Alto, CA.

Gough, H. G. and Heilbrun, A. B. (1983). The Adjective Check List Manual, Consulting Psychologists, Palo Alto, CA.

Gray, J. A. (1982). The Neuropsychology of Anxiety: An Enquiry into the Function of the Septohippocampal System, Oxford University Press, New York, NY.

Haier, R. J., Buchsbaum, M. S., Murphy, D. L., Gottesman, I. I., and Coursey, R. D. (1980). 'Psychiatric vulnerability, monoamine oxidase, and the average evoked potential', Archives of General Psychiatry, 37: 340-345.

Haier, R. J., Sokolski, K., Katz, M. and Buchsbaum, M. S. (1987). 'The study of personality with positron emission tomography'. In: Strelau, J. and Eysenck, H. J. (Eds), Personality Dimensions and Arousal, pp. 261--267, Plenum, New York, NY.

Hathaway, S. R. and McKinley, J. C. (1967). Minnesota Multiphasic Personality Inventory Manual, Revised 1967, The Psychological Corporation, New York, NY.

Hofstee, W. K. B. (1994). 'Who should own the definition of personality?' Presidential Address 
for the Seventh European Conference on Personality, Madrid, 12-16 July, 1994; European Journal of Personality, 8: 149-162.

Hofstee, W. K. B., De Raad, B. and Goldberg, L. R. (1992). 'Integration of the Big Five and circumplex approaches to trait structure', Journal of Personality and Social Psychology, 63: $146-163$.

Hogan, R. (1983). 'A socioanalytic theory of personality'. In: M. M. Page (Ed), Nebraska Symposium on Motivation 1982: Personality-Current Theory and Research, pp. 55-89, University of Nebraska Press, Lincoln, NE.

Hogan, R. (1986). Hogan Personality Inventory Manual, National Computer Systems, Minneapolis, $\mathrm{MN}$.

Hogan, R. and Hogan, J. (1992). Hogan Personality Inventory Manual, Hogan Assessment Systems, Tulsa, OK.

Hogan, R. and Johnson, J. A. (1979). 'The Hopkins Personality Inventory: a socioanalytic view of the structure of personality', unpublished manuscript, The Johns Hopkins University, Baltimore, MD.

Hogan, R. and Johnson, J. A. (1981). 'The structure of personality', paper presented at the 89th Annual Convention of the American Psychological Association, Los Angeles, CA, September, 1981.

Holland, J. L. (1985a). Making Vocational Choices: A Theory of Vocational Personalities and Work Environments (2nd Edn), Prentice-Hall, Englewood Cliffs, NJ.

Holland, J. L. (1985b). Vocational Preference Inventory (VPI) Manual 1985 Edn, Psychological Assessment Resources, Odessa, FL.

Horton, R. and Finnegan, R. (Eds) (1973). Modes of Thought: Essays on Thinking in Western and Non-western Societies, Faber and Faber, London.

Johnson, J. A. (1983). 'Criminality, creativity, and craziness: structural similarities in three types of nonconformity'. In: Laufer, W. S. and Day, J. M. (Eds), Personality Theory, Moral Development, and Criminal Behavior, pp. 81-105, Heath, Lexington, MA.

Johnson, J. A. (1990). 'Hardware store personnel selection with the Hogan Personality Inventory', unpublished paper, Pennsylvania State University, DuBois, PA.

Johnson, J. A. (1992). 'Multimethod replication of the AB5C model', paper presented at the Sixth European Conference on Personality, Groningen, 15-19 June, 1992.

Johnson, J. A. (1994a). 'Interpreter's Guide to the Bipolar Adjective Rating Scales (BARS)', Consulting Psychologists, Palo Alto, CA, in press.

Johnson, J. A. (1994b). 'The role of personality in reconcilable and irreconcilable theoretical differences'. In: McAdams, D. P. and Emmons, R. A. (Eds), Levels and Domains in Personality, (Journal of Personality Special Issue), in press.

Johnson, J. A., Germer, C. K., Efran, J. S. and Overton, W. F. (1988). 'Personality as the basis for theoretical predilections', Journal of Personality and Social Psychology, 55: 824-835.

Johnson, J. A. and Hogan, R. (1981). 'Vocational interests, personality, and effective police performance', Personnel Psychology, 34: 49-53.

Johnson, J. A. and Ostendorf, F. (1993). 'Clarification of the five factor model with the abridged big five dimensional circumplex', Journal of Personality and Social Psychology, 65: $563-576$.

Keen, S. (1973). " "We have no desire to strengthen the ego or make it happy" A conversation about ego destruction with Oscar Ichazo', Psychology Today, 7: 64-72.

Kelso, G. I. (1976). Exploration of the developmental antecedents of Holland's occupational types, Doctoral dissertation, Johns Hopkins University; Dissertation Abstracts International, 37: 440B.

Kemp, S. (1988). 'Personality in ancient astrology', New Ideas in Psychology, 6: 267-272.

Knapp, R. H. (1964). 'An experimental study of a triadic hypothesis concerning the sources of aesthetic imagery', Journal of Projective Techniques, 28: 49-54.

Kolb, D. A. (1976). LSI Learning Style Inventory Technical Manual, McBer, Boston, MA.

Laufer, W. S., Johnson, J. A. and Hogan, R. (1981). 'Ego control and criminal behavior', Journal of Personality and Social Psychology, 41: 179-184.

Leone, S. (1973). 'Associational-metaphorical activity: another view of language and mind', American Anthropologist, 75: 1276-1281. 
MacDonald, K. (1991). 'A perspective on Darwinian psychology: domain-general mechanisms, plasticity, and individual differences', Ethology and Sociobiology, 12: 449-480.

MacDonald, K. (1994). 'Evolution, the five factor model, and levels of personality'. In: McAdams, D. P. and Emmons, R. A. (Eds), Levels and Domains in Personality, (Journal of Personality Special Issue), in press.

Makarec, K. and Persinger, M. A. (1985). 'Temporal lobe signs: electroencephalographic validity and enhanced scores in special populations', Perceptual and Motor Skills, 60: 831842.

Makarec, K. and Persinger, M. A. (1990). 'Electroencephalographic validation of a temporal lobe signs inventory in a normal population', Journal of Research in Personality, 24: 323-337.

Martindale, A. E. and Martindale, C. (1988). 'Metaphorical equivalence of elements and temperaments: empirical studies of Bachelard's theory of imagination', Journal of Personality and Social Psychology, 55: 836-848.

Maslow, A. (1957). 'Two kinds of cognition and their integration', General Semantics Bulletin, 20/21: 17-22.

McCrae, R. R. (1987). 'Creativity, divergent thinking, and openness to experience', Journal of Personality and Social Psychology, 52: 1258-1265.

McCrae, R. R. (1990). 'Traits and trait names: How well is Openness represented in the natural language?' European Journal of Personality, 4: 119-129.

McCrae, R. R. (1994). 'Openness to experience: expanding the boundaries of Factor V'. In: De Raad, B. and Van Heck, G. L. (Eds), The Fifth of the Big Five, (European Journal of Personality Special Issue), 8: 251-272.

McCrae, R. R. and Costa, P. T., Jr. (1985). 'Openness to experience'. In: Hogan, R. and Jones, W. H. (Eds), Perspectives in Personality, Vol. 1, pp. 145-172, JAI, Greenwich, CT.

McCrae, R. R. and Costa, P. T., Jr. (1992). 'Discriminant validity of NEO-PI-R facet scales', Educational and Psychological Measurement, 52: 229-237.

Musès, C. (1972). 'A note on psychological typology', Journal for the Study of Consciousness, 5: $91-93$.

Neisser, U. (1963). 'The multiplicity of thought', British Journal of Psychology, 54: 1-14.

Norman, W. T. (1963). 'Toward an adequate taxonomy of personality attributes: replicated factor structure in peer nomination personality ratings', Journal of Abnormal and Social Psychology, 66: 574-583.

Peabody, D. and Goldberg, L. R. (1989). 'Some determinants of factor structures from personality-trait descriptors', Journal of Personality and Social Psychology, 46: 384-403.

Piedmont, R. L., McCrae, R. R. and Costa, P. T., Jr. (1991). 'Adjective Check List scales and the Five-Factor Model', Journal of Personality and Social Psychology, 60: 630-637.

Reynolds, C. H. and Nichols, R. C. (1977). 'Factor scales of the CPI: do they capture the valid variance?', Educational and Psychological Measurement, 37: 907-915.

Royce, J. R. (1964). The Encapsulated Man: an Interdisciplinary Essay on the Search for Meaning, Van Nostrand, Princeton, NJ.

Samuel, W. (1981). Personality: Searching for the Sources of Human Behavior, McGraw-Hill, New York, NY.

Saucier, G. (1992). 'Openness versus Intellect: Much ado about nothing?' European Journal of Personality, 6: 381-386.

Strong, E. K., Jr. (1959). Manual for Strong Vocational Interest Blanks for Men and Women, Consulting Psychologists, Palo Alto, CA.

Tellegen, A. (1994). Manual for the Multidimensional Personality Questionnaire, University of Minnesota Press, Minneapolis, MN.

Tellegen, A. and Atkinson, G. (1974). 'Openness to absorbing and self-altering experiences ("absorption"), a trait related to hypnotic susceptibility', Journal of Abnormal Psychology, 83: $268-277$.

Tomkins, S. S. (1965). 'Affect and the psychology of knowledge'. In: Tomkins, S. S. and Izard, C. E. (Eds), Affect, Cognition, and Personality, pp. 72-97, Springer, New York, NY.

Trapnell, P. (1992). 'Vocational interests and the facet structure of Factor V'. In: Kihlstrom, J. F. (Chair), Intellectance and Openness in the 'Big Five' Personality Structure, symposium 
conducted at the Annual Convention of the American Psychological Association, Washington, DC, August, 1992.

Trapnell, P. D. and Wiggins, J. S. (1990). 'Extension of the Interpersonal Adjective Scales to include the Big Five dimensions of personality', Journal of Personality and Social Psychology, 59: 781-790.

Welsh, G. S. (1975). Creativity and Intelligence: A Personality Approach, Institute for Research In Social Science, Chapel Hill, NC.

Welsh, G. S. (1977). 'Personality correlates of intelligence and creativity in gifted adolescents'. In: Stanley, J. C., George, W. C. and Solano, C. H. (Eds), The Gifted and the Creative: A Fifty-year Perspective, pp. 197-221, Johns Hopkins, Baltimore, MD.

Welsh, G. S. (1980). Manual for the Welsh Figure Preference Test Revised Edn, Consulting Psychologists, Palo Alto, CA.

Werner, H. (1955). 'A psychological analysis of expressive language'. In: Werner, H. (Ed), On Expressive Language, pp. 12-18, Clark University Press, Worcester, MA.

Wicklund, R. A. (1990). Zero-variables Theories and the Psychology of the Explainer, SpringerVerlag, New York.

Wiggins, J. S. (1979). 'The psychological taxonomy of trait-descriptive terms; the interpersonal domain', Journal of Personality and Social Psychology, 37: 395-412.

Wiggins, J. S. and Broughton, R. (1991). 'A geometric taxonomy of personality scales', European Journal of Personality, 5: 343-365.

Zuckerman, M. (1989). 'Personality in the third dimension: a psychobiological approach', Personality and Individual Differences, 10: 391-418.

Zuckerman, M. (1990). 'The psychophysiology of sensation seeking', Journal of Personality, 58: $313-345$. 